\title{
206 IMPACT OF LEVEL OF PARTICIPATION ON AGGRESSION, ANXIETY, ACHIEVEMENT MOTIVATION AND PERFORMANCE AMONG SOCCER PLAYERS
}

Siva Sankar Reddy Mudimela Department of Physical Education, Sri Venkateswara

University, Tirupati, Andhra Pradesh, India

\subsection{6/bjsm.2010.078725.206}

An attempt has been made to study the impact of level of participation on psychological factors such as aggression, anxiety, achievement motivation and performance. Six hundred and twenty-five soccer players representing three different levels that is, inter-university, inter-district, inter-collegiate, constituted the sample of the study.

Sports CompetitionAnxietyTest(Marten1977), Aggressiveness Questionnaire (Smith 1973), Sports Achievement Motivation Test (Kamalesh 1983) were administered to assess anxiety, aggression and achievement motivation, respectively. The performance of soccer players was assessed by using rating scale (rating scale for evaluation of playing ability by experts for soccer players (Pown Radha 1996). One-way analysis of variance and stepwise multiple regression analysis were employed to analyse the data. Significant differences were found among three levels of participation with regard to aggression achievement motivation and performance only. Aggression and achievement motivation contributed significantly to performance whereas anxiety is found to have negative impact on the performance. 